\title{
Improving health system efficiency for better health outcomes
}

The World Health Organization (WHO) placed "value for money" as an important element to move countries towards Universal Health Coverage (UHC) in its 2010 World Health Report, stressing that health systems should pay attention to improving efficiency of using existing funding for better health outcomes (1). A significant amount of health resources are wasted, which would saving millions of lives if they were used wisely and efficiently. The efficiency of using available funding, along with the innovations to generate new resources for health, is critical for achieving UHC. This special series compiles studies that aims to improve the health system efficiency in Afghanistan, Nigeria, Ukraine, Haiti, Botswana and Zimbabwe.

Zeng and colleagues evaluate the cost-effectiveness of two financing programs in Nigeria: one is performance-based financing that tied payments to performance indicators, and the other is decentralized facility financing program where payments to health facilities were unconditional. Both programs show promising results in providing essential maternal and child health services. The result suggests that financial incentives can improve the use of underutilized essential services in low- and middle-income countries.

Shepard et al. investigate the cost-effectiveness of a similar program in Zimbabwe. The evaluation combined the impact of the performance-based financing on both quality and quantity of target health services. The study shows that the program was associated with the improvement of use of key maternal and child health services. However, the impact of the program on quality improvement was minimal. Overall, the program demonstrates a cost-effective health system investment.

In the same country, Mutasa et al. focus on the effect of the performance-based financing program on quality of care only. The result is consistent to what reported in Shepard's article, showing that the performance-based financing program only has an impact on quality for care for institutional deliveries. However, there are a wide variety of contextual variables that may affect the program's effectiveness, including population wealth and availability of human resources. The article highlights that incentive payment programs should be accustomed to the local context to maximize their potential.

At the health facility level, Avila and colleagues examine the efficiency of providing antiretroviral treatment (ART) services in Botswana and find a wide range of performance in delivering ART services in the country. One important finding is that the performance of ART services is lower in hospitals than health posts, suggesting the potential to scale up the ART to the lower level of health systems to improve the coverage of the care. The authors suggest decentralizing ART services to primary health care delivery points for better efficiency.

In Haiti, Mekonen and colleagues evaluate health facility efficiency of delivering primary health services. The study identifies the critical association between health workforce and the efficiency of health facilities in the county. As many countries are facing a shortage of health human resources and challenges of disruptive medical health services, this study sheds light on strengthening health human resources as a means to improve the efficiency of primary health care systems.

In Ukraine, Avila reviews the evolvement of health financing policies in the country. The article highlights the weaknesses of health financing system in the past, and describes the process of health financing reforms that have been undertaken. The review highlights the critical role of strategic purchase as a lever to overhaul the health system in Ukraine to promote the efficiency improvement.

In Afghanistan, Farewar and colleagues take the angle of equity to assess the disparity of use of health care services. After health care reforms for more than a decade, there exist inequity in using health care services. The inequity is more salient in using inpatient care and private health services than outpatient care. As Afghanistan still heavily relies on the private sector to provide essential health services, addressing the concern of unequal access to care becomes a prominent issue in the country.

In summary, efficiency is an important topic in strengthening health systems, and approaches to evaluating the efficiency have been evolving. The articles that are compiled in this specifical series provide empirical evidence of efficiency evaluation at the health facility and health system levels, and methodology to conduct the evaluation. 


\section{Acknowledgments}

Funding: None.

\section{Footnote}

Provenance and Peer Review: This article was commissioned by the editorial office, fournal of Hospital Management and Health Policy for the series "Incentives and Health System Efficiency in Low- and Middle-income Countries". The article did not undergo external peer review.

Conflicts of Interest: The author has completed the ICMJE uniform disclosure form (available at https://jhmhp.amegroups. com/article/view/10.21037/jhmhp-21-77/coif). The series "Incentives and Health System Efficiency in Low- and Middleincome Countries" was commissioned by the editorial office without any funding or sponsorship. WZ served as the unpaid Guest Editor of the series and serves as an unpaid editorial board member of fournal of Hospital Management and Health Policy from August 2019 to July 2021. The author has no other conflicts of interest to declare.

Ethical Statement: The author is accountable for all aspects of the work in ensuring that questions related to the accuracy or integrity of any part of the work are appropriately investigated and resolved.

Open Access Statement: This is an Open Access article distributed in accordance with the Creative Commons AttributionNonCommercial-NoDerivs 4.0 International License (CC BY-NC-ND 4.0), which permits the non-commercial replication and distribution of the article with the strict proviso that no changes or edits are made and the original work is properly cited (including links to both the formal publication through the relevant DOI and the license). See: https://creativecommons.org/licenses/by-nc$\mathrm{nd} / 4.0 /$.

\section{References}

1. World Health Organization. The world health report: health systems financing: the path to universal coverage. Geneva: World Health Organization, 2010. 


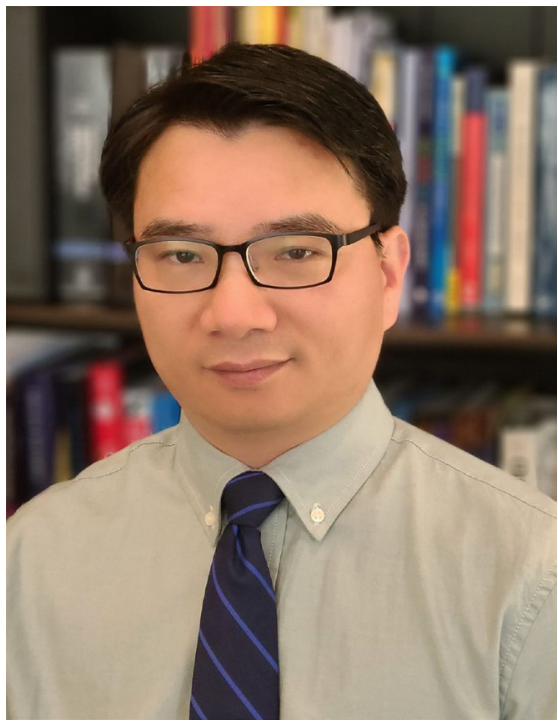

Wu Zeng

Wu Zeng

Department of International Health, School of Nursing and Health Studies, Georgetown University, Washington, DC, USA.

(Email:Wz192@georgetown.edu)

Received: 09 October 2021; Accepted: 01 November 2021; Published: 25 June 2022.

doi: $10.21037 /$ jhmhp-21-77

View this article at: https://dx.doi.org/10.21037/jhmhp-21-77

doi: $10.21037 /$ jhmhp-21-77

Cite this article as: Zeng W. Improving health system efficiency for better health outcomes. J Hosp Manag Health Policy 2022;6:11. 